10. Fonrouge, C. (2008). Entrepreneuriat et innovations organisationnelles. Revue Française de Gestion, 34 (185), 107-123. doi: https://doi.org/10.3166/rfg.185.107-123

11. Brosia, S. (2016). Management strategique de Start up innovantes et creation de valeurs. Gestion et management. Universite de Toulon. HAL. Available at: http://docplayer.fr/50860535-Management-strategique-de-start-up-innovantes-et-creation-de-valeurs.html

12. Brown, T. (2008). Design Thinking. Harvard business review. Available at: https://readings.design/PDF/Tim\%20Brown,\%20 Design\%20Thinking.pdf

The main goal of the study is to identify global digital e-marketing trends in the world. The paper discusses the main aspects of the functioning of companies on the basis of the formation of the classical concept of marketing. The main constituent elements of the classical marketing concept, its advantages and disadvantages are highlighted. Based on the structuring of the main theoretical aspects of marketing development, the evolution of marketing concepts with historical aspects and their characteristics has been formed. The necessity of rethinking the existing business models of companies, which should be based on innovative e-marketing tools, is argued. The main ways and types of transformation of the classical concept of marketing in modern business conditions are highlighted. It has been shown that constant modernization, optimization and improvement of the efficiency of business processes are ensured through the implementation of key elements of e-marketing. Based on a critical analysis and generalization of existing approaches in organizing marketing activities, it is substantiated that ensuring the competitive position of a company on a world level is impossible without the use of $e$-marketing. The global trends of digitalization of e-marketing in the world were considered and identified. The presented goal is achieved by using the tools of economic and statistical analysis of modern trends in the development of e-marketing and a theoretical and methodological approach to identifying and structuring the main development trends, their directions, and main types. The obtained results of economic and statistical forecasting can be applied in practice in the formation of a company's marketing strategy, taking into account modern trends in the development of innovations

Keywords: e-marketing, global, digitalization, trends, e-marketing strategy, marketing concept, economic and statistical forecasting
UDC 339.138:004.738.5

DOI: $10.15587 / 1729-4061.2022 .252276$

\section{RESEARCHING GLOBAL DIGITAL E-MARKETING TRENDS}

\author{
Hassan Ali Al-Ababneh \\ Corresponding author \\ $\mathrm{PhD}$ in Economics \\ Department of $\mathrm{E}$ - Marketing and \\ Social Communication \\ Irbid National University \\ Bat-haa str., 10A, Mafraq, \\ Jordan, 21110 \\ E-mail: hassan_ababneh@inu.edu.jo
}

\section{Introduction}

In the context of the global transformation of the world economy under the influence of volatility and uncertainty caused by the COVID-19 pandemic and imbalances in world trade, it is undoubtedly urgent to develop and emerge new approaches, methods and tools for business management. The main purpose of the study is to find and develop innovative management approaches that should provide opportunities for optimizing core activities in order to increase efficiency and minimize operating costs. An important argument in the presented is that modern business processes in most cases cannot be imagined without using the marketing concept as one of the components of the company's strategy. Marketing and all its main manifestations are constantly being improved and developed, which suggests that this direction is relevant and in demand recently.

The relevance of the study lies in the need for constant promotion, positioning and business development in an already established business niche every day only increases. Providing a solution to the described tasks for any top management of an organization or company is impossible without the use of modern innovations and information and telecommunication technologies, which every day play an increasingly important role in business. The intensity of the development of information and telecommunication technologies has made it possible to form a virtual environment for doing business and establishing relations between business entities.

The need for an in-depth study and analysis of this topic is justified by the rapid pace of popularization of global digitalization in all spheres of the world economy, which confirms the absence of a single universal toolkit for doing business in the virtual space.

\section{Literature review and problem statement}

The transformation of the world economy significantly complicates the processes of management and doing business, which, in turn, negatively affects economic growth both in individual industries and in individual countries. The complexity of company management and the main levers of increasing the efficiency of core activities are inextricably linked with the use of innovative marketing approaches, namely electronic marketing. The development of the information society, the digitalization of the global economy require the use of electronic marketing, since consumers prefer those brands that quickly master digital channels, tools and methods of building relationships. It is worth noting that it is email marketing that is intended to change the modification of communication activities. The paper [1] is devoted to the study of the main theoretical aspects of the development of electronic marketing, in which the trends in 
the development of electronic marketing in various sectors of the world economy are considered, but the main features of its constituent innovative instruments are not highlighted, which requires a deeper study.

Part of the problems associated with the specifics of the development of strategic marketing in a crisis is considered in the study [2], which examines the process of forming marketing strategies, taking into account the marketing mix based on the use of innovative tools and technologies in the crisis caused by COVID-19. It should be noted that an unresolved problem remains the fact that the current trends in the development of digital marketing are not taken into account, which does not allow conceptually to accurately determine trends and requires more detailed study and research.

It should be noted that the study of the main aspects of marketing development using modern innovative Internet technologies is considered by such scientists as [3], who will highlight in their scientific works one of the most important marketing tools - the use of Internet technologies. However, this study does not reveal the main trends in marketing development and is narrowly focused, which does not allow judging about an exhaustive study in this direction. The use of Internet technology is considered in scientific [4] the peculiarities of marketing organization using innovations, which does not reveal the peculiarities of the formation of trends in the development of digital marketing. However, an unresolved part of this problem remained the issues of studying the key specific differences between Internet marketing and digital marketing, which requires a more indepth analysis and determines the relevance and necessity of the research topic.

Special attention to the organization of marketing in modern conditions is considered in the study [5], in which the inseparable connection between marketing and logistics, as a single mechanism of any company, is highlighted. It should be noted that the considered problem of marketing organization in modern conditions is relevant, but does not determine global trends in the development of digital marketing, which requires a more detailed study.

Partial consideration is given to the problem associated with the allocation of the main trends in marketing development, which examines modern marketing trends and their impact on the consumer, taking into account the economic cycles of the world market [6]. However, it should be noted that this approach does not fully disclose the essence of the problem under study and is more aimed at studying the characteristics of consumer behavior in the modern world at various stages of the life cycle of goods and services, and not at how this is done, at studying trends in the development of electronic marketing.

Digital marketing trends are evident in the study [7], which substantiates the conceptual role of digital marketing in modern society and its impact on consumers. However, given the reviewed trends in this approach, it will not be possible to single out global trends in the development of digital marketing, which proves the relevance of this study and the need for detailing. In view of the above, it is worth noting that the lack of a unified approach to determining global trends in the digitalization of electronic marketing is causing more and more interest in a more in-depth study and argumentation of its need for further analysis.

\section{The aim and objectives of the study}

The aim of the study is to determine global trends in the development of digital marketing in the world, taking into account modern conditions of intensive development of innovations, transformation of the world market and the need for constant modernization of existing management methods, which will develop practical recommendations for the formation of effective marketing management strategy for any company.

To achieve this aim, the following objectives are accomplished:

- to form an evolutionary approach to the definition of marketing concepts with historical aspects and their characteristics:

- to structure the main components of the classical marketing concept, its advantages and disadvantages;

- to justify the need to rethink the existing business models of companies;

- to determine the main ways and types of transformation of the classical concept of marketing in modern business conditions;

- to conduct an economic and statistical analysis and solve the problem of forecasting global trends in digital marketing digitalization in the world.

\section{Materials and methods}

To determine the global trends in the development of electronic marketing and the introduction of the main innovative tools and digital methods in it, it is worth using the basic tools of economic and statistical analysis and forecasting. To substantiate the global trends in digitalization of electronic marketing, to conduct economic and statistical analysis and further forecasting, the main indicator was chosen - the volume of sales using digital marketing and its main tools, as well as the volume of expenses and income of electronic marketing. The use of tools for economic and statistical analysis and further forecasting of the target indicators of electronic marketing will be carried out on the basis of a trend model. These models are determined by substituting the selected indicator $(n)$ into the equation, the value of the study time period $(t)$, which corresponds to the period of this study:

$$
t=n+1 ; \quad t=n+2 .
$$

The calculation of the confidence intervals depends on $t$ standard error in assessing the global trends in digitalization of e-marketing, which is predicted and the time ahead of the forecast, on the number of levels in the time series and on the level of significance (error) of the forecast. The quality and reliability of the results obtained are determined on the basis of:

$$
R^{2}=\frac{\sum_{i=1}^{n}(y-\bar{y})^{2}}{\sum_{i=1}^{n}\left(y_{i}-\bar{y}\right)^{2}},
$$

where $y$ - theoretical values of e-marketing indicators in the world; $o$ - overall average of the actual data of the dynamics indicators; $y_{i}-$ actual individual values of the indicators of the dynamics of e-marketing development in the world. 


\section{Results of the study of global e-marketing digitalization trends}

\section{1. An evolutionary approach to the definition of marketing concepts with historical aspects and their features}

The constant growth of competition in domestic and foreign markets, the globalization of economic relations, fundamental changes in innovative technologies and means of promoting products, methods of influencing consumers cause an increase in the interest of top management of leading organizations and companies in the requirements of organizing marketing activities to ensure their efficiency and profitability. It should be argued that in modern conditions, to obtain and maintain competitive advantages, many organizations and companies constantly analyze markets, competitors, goods, consumers; improve products and improve themselves; use non-standard solutions in advance to promote products on the market, that is, carry out strategic planning of innovation and marketing activities.

Marketing is the purposeful use of market policy instruments that are focused on meeting the needs of consumers. In other words, marketing is the company's activity in the field of market research, not only in the area of interests of sales and distribution activities, but also in predicting the possible behavior of the market for a new product. In the face of heightened competition in the world market and an unstable market environment, the organization of any activity is forced to constantly search for methods to ensure sustainable development. To determine the global trends in the digitalization of electronic marketing, it is worth considering the evolutionary and historical development of marketing in the world, which is presented in Table 1.

It should be stated that the new paradigm in the development of marketing in the world, according to many scientists and marketers, falls on the $60-80$ s, this is due to the transition of economically developed countries from the industrial to the post-industrial period. This is explained by the fact that in the presented historical development and evolution of marketing, the transition from mass to individual production, the differentiation of the world market and the need to optimize costs, increase incomes significantly determine the intensive development of innovations and advanced technologies with their further application in marketing [7].

Modern business actively uses all the existing possibilities of information technology in its core business. It is also worth noting that in most cases, with effective top management of the company and the use of digital technologies in marketing, the level of such use ensures the success of doing business, both in the domestic and global markets. Globalization and the transition to the digital economy significantly increase the demand for modern innovations in the field of marketing, as evidenced by the developed evolution of marketing and the constant modernization of existing marketing concepts and their practical application in the main activities of companies.

It is important to note that in the modern world, in view of the increasing competition, the use of a classic marketing mix is not always enough. Therefore, many scientists and marketers are constantly expanding and modernizing the list of key components of marketing, in connection with which new concepts are formed and global development trends are determined.

Table 1

Historical aspects of development and evolution of marketing in the world

\begin{tabular}{|c|c|c|}
\hline $\begin{array}{l}\text { A period of } \\
\text { time }\end{array}$ & $\begin{array}{l}\text { Specificity of the evolu- } \\
\text { tionary stage }\end{array}$ & $\begin{array}{c}\text { Evolutionary marketing } \\
\text { concept }\end{array}$ \\
\hline $\begin{array}{l}\text { Late } 19^{\text {th }}-\text { early } \\
20^{\text {th }} \text { centuries }\end{array}$ & $\begin{array}{l}\text { Intensive development } \\
\text { of the economy, mass } \\
\text { production, invention of } \\
\text { the DC generator, electric } \\
\text { motor, internal combus- } \\
\text { tion engine }\end{array}$ & $\begin{array}{l}\text { Marketing concept, } \\
\text { which was aimed at the } \\
\text { development of production } \\
\text { and production facilities. } \\
\text { Reducing the cost of a } \\
\text { product and its price - } \\
\text { success in the market }\end{array}$ \\
\hline $1930-1950$ & $\begin{array}{l}\text { Rapid increase in pro- } \\
\text { duction capacity and } \\
\text { saturation with goods }\end{array}$ & $\begin{array}{l}\text { The concept of sales } \\
\text { marketing is aimed at } \\
\text { promoting a product, } \\
\text { since the market is over- } \\
\text { saturated with a product }\end{array}$ \\
\hline $1960-1980$ & $\begin{array}{l}\text { An increase in the share } \\
\text { of new technologies in } \\
\text { production, which makes } \\
\text { it possible to improve the } \\
\text { quality of goods and pro- } \\
\text { vide a wider assortment }\end{array}$ & $\begin{array}{l}\text { The concept of marketing } \\
\text { is transformed into an } \\
\text { entrepreneurial func- } \\
\text { tion, which is aimed at } \\
\text { satisfying the need for a } \\
\text { manufactured product }\end{array}$ \\
\hline $1980-1999$ & $\begin{array}{l}\text { Implementation and emer- } \\
\text { gence of new technologies, } \\
\text { which allows to increase } \\
\text { the volume of production, } \\
\text { improve the quality and } \\
\text { value of goods }\end{array}$ & $\begin{array}{l}\text { Marketing concept aimed } \\
\text { at improving the quality } \\
\text { of service and meeting } \\
\text { the needs of the consumer }\end{array}$ \\
\hline $2000-2007$ & $\begin{array}{l}\text { The crisis period in the } \\
\text { world economy, instability } \\
\text { and sharp dynamics of } \\
\text { prices for raw materials, } \\
\text { which leads to an increase } \\
\text { in the cost of goods with } \\
\text { the same quality and } \\
\text { production volumes }\end{array}$ & $\begin{array}{l}\text { The concept of market- } \\
\text { ing, which is based on the } \\
\text { use of all basic con- } \\
\text { cepts that are aimed at } \\
\text { increasing product sales, } \\
\text { promoting, improving } \\
\text { service to gain competi- } \\
\text { tive positions }\end{array}$ \\
\hline $\begin{array}{l}\text { 2008-present } \\
\text { time }\end{array}$ & $\begin{array}{l}\text { Rapid development of } \\
\text { innovative tools and } \\
\text { information and Internet } \\
\text { technologies and their use } \\
\text { in production }\end{array}$ & $\begin{array}{l}\text { The concept of internet } \\
\text { marketing, which is based } \\
\text { on the sale, promotion } \\
\text { and service through the } \\
\text { use of internet and digital } \\
\text { technologies }\end{array}$ \\
\hline
\end{tabular}

5. 2. Structuring the main components of the classic marketing concept, its advantages and disadvantages

The functioning of any business today is characterized by the individual nature of communication between producers and consumers, the convenience of the process of choosing and purchasing goods and services, ample opportunities to provide the consumer with the necessary information, the purposefulness of information impact; the ability to establish ongoing business relationships with consumers, measure their response to relevant requests; high efficiency of creating information messages and the ability to adjust them depending on the reaction of consumers. In the modern world, the use of the classic marketing mix is not always sufficient and effective, but as a basic level of the company's strategy, in any case, it should include the set of components, which is presented in Table 2.

The intensity of the processes of globalization of the world market is characterized by the massive digitalization of business areas, which in turn actualizes the development of new forms of doing business and the emergence of new concepts of digital marketing. These processes cause human 
society to become information-rich, and information is the main product with which this or that person will deal in their activities. Consequently, in the era of digitalization of all sectors of human life, there are a number of factors that determine the intensive development and application of innovative technologies in practice, which are aimed at optimizing the company's business processes and increasing efficiency.

Table 2

Essential elements of the classic marketing concept

\begin{tabular}{|c|c|}
\hline $\begin{array}{c}\text { Marketing } \\
\text { element }\end{array}$ & $\begin{array}{c}\text { Characteristics of the main element of the classical } \\
\text { marketing concept }\end{array}$ \\
\hline Product & $\begin{array}{c}\text { Products sold using Internet technologies are of high } \\
\text { quality. Such products are able to compete not only } \\
\text { with other online stores, but also with traditional stores. } \\
\text { Marketing technologies of companies in the modern } \\
\text { scientific and technical environment }\end{array}$ \\
\hline Price & $\begin{array}{c}\text { The price level in online stores is considered to be } \\
\text { lower than the price level in conventional stores, due } \\
\text { to cost savings }\end{array}$ \\
\hline $\begin{array}{c}\text { Promo- } \\
\text { tion }\end{array}$ & $\begin{array}{c}\text { A set of activities aimed at promoting both the site itself } \\
\text { and the product using digital channels. These tools } \\
\text { cover a large arsenal of tools: search engine optimiza- } \\
\text { tion, contextual advertising, banner advertising, e-mail } \\
\text { marketing, affiliate marketing, viral marketing, hidden } \\
\text { marketing, interactive advertising, blogging, etc. }\end{array}$ \\
\hline Place & $\begin{array}{c}\text { The place of sale is the website. Sales success depends } \\
\text { on graphic design, convenience, quality and speed of } \\
\text { processing requests from the site, etc. }\end{array}$ \\
\hline
\end{tabular}

5. 3. Justification of the need to rethink the existing business models of companies

In business, the concept of marketing is a strategy for the development of a company, organization or even an entire holding in a market economy, focused on a specific consumer. The strategy is aimed at satisfying its needs, while simultaneously solving the tasks and goals set by the business: sales growth, revenue increase, conquering new markets, expanding the offered assortment and increasing customer loyalty. In a historical perspective, there was a shift in emphasis from the production of goods to their marketing, and then to solving problems that generally arise before society and consumers.

The process of forming a strategy for the company is very important and takes place in the following situations:

1) when creating a new business project;

2) with a decrease in the company's competitiveness indicators;

3) division of a business or brand between different founders;

4) a change in the top management of the company and a tangible decrease in the revenue side;

5) the need to identify new goals and opportunities for long-term growth. In all the cases presented, the company's management will have to make a managerial decision on which marketing concept to be guided and what key components to focus on when organizing core activities.

It should be emphasized that in the modern world in the context of constant transformation and updating of existing approaches in marketing, many scientists, marketers and managers are con- stantly expanding the list of elements of the classic marketing concept "4P" - (Product, Price, Promotion, Place), in connection with how new concepts "7P", "8P" ... "12P" are formed.

5.4. The main ways and types of transformation of the classical concept of marketing in modern business conditions

Digitalization of all spheres of human activity entails an intensive transformation of marketing, the development and application of new tools, methods and elements in the marketing concept. The transition from traditional aggressive marketing tools for promoting and positioning goods and services to "native adds" and "earned media", which expand the boundaries to increase consumer loyalty through dialogue, offering them a truly valuable product. The composition of digital media, in addition to the Internet, includes digital television, radio, monitors, displays and other digital means of communication.

To determine and formulate scientific and practical recommendations for determining global trends in the development of digital marketing in the world, it is worth noting that digital marketing does not include promotion through such traditional channels as newspaper ads, flyers, TV advertising, billboards. From the point of view of marketing communications, it involves the use of all possible forms of digital channels for brand promotion. Digital marketing communications allow you to reach your target audience in an offline environment.

The popularity of such channels and resources in business and the activation of e-commerce indicate the relevance of the use of tools and elements of electronic marketing and, at the same time, are favorable factors for the successful achievement of the marketing goals of companies and organizations at the global level. However, it should be noted that the effectiveness of email marketing for each individual organization or company depends on specifically selected tools, the use of which will not only achieve the desired results, but also get ahead of competitors in the market and get many new attractive opportunities for business development [8].

It is worth arguing for the fact that email marketing is significantly different from conventional marketing communications due to the use of virtual information space. The Internet and other digital media (smart TV, smartphones and tablets) open up new forms of interaction and new models of information exchange. One of the first comprehensive studies of the difference between new digital trends and traditional marketing came from $[9,10]$, which formulated the $6 \mathrm{P}$ model of email marketing. Based on the above, for conceptualizing and highlighting the features of the development of electronic marketing, it is worth considering its key elements, which are presented in Fig. 1.

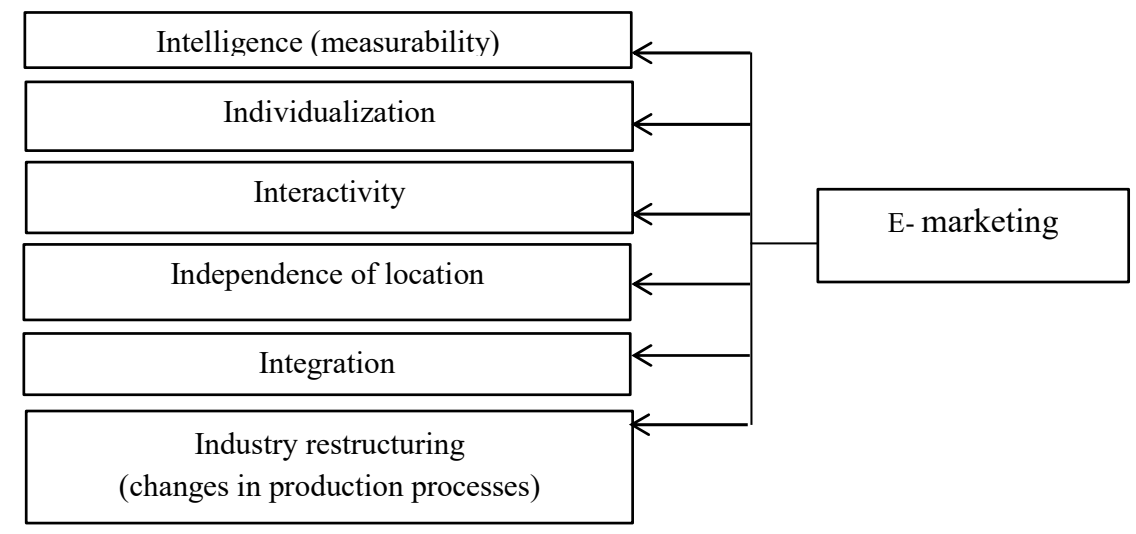

Fig. 1. Features and benefits of e-marketing in modern conditions 
The high interactivity of electronic marketing as an information medium is due to the following:

1) the client himself initiates the contact;

2) the client himself is looking for information about brands and products;

3) the use of the Internet requires high human involvement, in contrast to radio or television, which can be listened to and watched in the background. The use of Internet technologies in electronic marketing allows you to post videos and audio recordings of any length for free, use polls, initiate discussions between people, create interactive games and applications. Measurability in the concept of electronic marketing is characterized by the fact that the Internet can be used as a relatively inexpensive way to conduct marketing research using CAPI technology (Computer-assisted personal interviewing). These tools allow you to process data about users, segment them and predict consumer behavior.

Electronic marketing trends are characterized by adaptation and individualization for each individual or individual segment of consumers. Consumers always welcome a personalized approach to service, which in turn improves the competitive position of the organization and increases audience loyalty to the brand. The development of innovations and information technologies and their application in the concept of electronic marketing in the world provides additional opportunities for integrated marketing communications. The emergence of the concept of electronic marketing gave rise to the development of the theory of "zero moment of truth", which assumes that before making a purchase, users actively explore the Internet to obtain additional information about the product, including studying the consumer experience of using the product by other people.

According to many surveys, depending on the product category, up to $70 \%$ of people say they look at product reviews before buying. Thus, an advertisement seen on television or on an outdoor billboard and heard on the radio in most cases is an incentive not to visit a store, but to search for information on the Internet about a company, product or service. This is why email marketing plays an important role in the overall integration of brand marketing activities. The emergence of the Internet has significantly changed the essence of intermediary relations in business. For a marketer who is developing a communication strategy for his company, it is very important to consider how the brand can be represented on the websites of resellers and what intermediaries are generally needed to ensure distribution on the Internet.

Electronic marketing allows you to expand the coverage of an advertising campaign throughout the Internet in all countries of the world, without reference to location. This argument opened up an opportunity for companies and organizations of all levels to sell goods and provide services on the international market, which was previously available only to large corporations and holdings.

Therefore, it is worth noting that in the modern world, the use of electronic marketing tools for many companies and organizations provides competitive advantages in various ways. The use of innovative e-marketing tools allows for effective management, low costs compared to traditional marketing tools. Based on this, it is worth considering the current trends in the development of electronic marketing in the world and the main advantages of its use in the real business segment.

Modern intensive trends in the development of information technologies and innovations lead to the fact that more and more they have found their application in all sectors of the world economy. However, in many industries and countries, there is still opposition to digitalization and automation of business processes in companies and spheres of human life. It should be noted that in the modern conditions of business functioning, marketing, in most cases, relies on customer experience and the involvement of employees in loyalty programs, brand promotion to enhance the impact on consumers. In view of the above, it is worth noting that marketing continues to transform and expand across all sectors of the global economy.

Marketing and its forms of manifestation have long gone beyond the standard methods of branding, advertising and promotion. The whole marketing transformation presented and its constant modernization within the framework of the adopted concept are because in the company, marketers must work closely together with other lines of business in order to focus on creating excellent customer experiences and attracting them for long-term relationships in the long term.

Modern business trends are because you should not invest in marketing programs that impose goods and services on consumers. This is because there is no point in imposing purchases, since the consumer is sufficiently aware of what he needs to buy and at what moment. This argument allows many marketers and marketing professionals to shift their priority to providing quality customer service that will keep shoppers coming back for new purchases. This allows us to highlight the key trend of electronic marketing in modern conditions - entrepreneurs should focus on building a positive business culture by providing exceptionally high-quality services, and marketers are required to transform business ideas into adequate and competitive marketing strategies.

In the modern world of marketing, the growth of useful and free content available has given consumers significantly more opportunities that are associated with the following: they ceased to depend on consultants and can study the product or service offered on the market in advance. Modern email marketing trends have driven consumers who are not looking for advice from sellers on what is best for them; instead, they are looking for information on the Internet, reading reviews and evaluating offers for purchases. It is important to note that the modern customer relies on the judgment of their marketing research, so marketers must offer more than information. Customer satisfaction, convenience in purchasing, competent and friendly service, convenient payment methods - these are the key values of consumers in their experience of interacting with companies.

A weighty argument in the effective formation of a marketing strategy and the development of electronic marketing in the modern world is the company's personnel, who must actively participate in the process of quality service. If employees are poorly trained or inadequately qualified, the customer or prospect will be unhappy and unlikely to return. What prevents staff from becoming active? The bad attitude of top management towards employees is the number one factor that prevents clients from doing business with a reliable company.

Global trends in the development of electronic marketing in the world are characterized by the fact that the staff is the face of the brand, so attention should be focused on the interaction of employees with potential customers and regular customers - end consumers. This is an important factor in any marketing strategy.

The key to employee engagement is to take proactive measures that enable each employee to understand business goals and brand values. When a manager hires a person, they plan to make the person responsible for providing quality customer 
service. It is necessary to provide measures that give confidence that the staff will strive for the success of the company as responsibly as its owner. Otherwise, employees will stop caring about customers. If they are not happy with the work and don't believe in the way the business is being conducted, they will not be able to achieve a positive customer experience.

\section{5. Statistical and economic analy-} sis of trends in digital marketing development in the world: forecasting of global trends in digital marketing digitalization

Modern trends in the development of electronic marketing in the world have intensively implemented the use of voice search tools and broadcasting content through the dynamics of consumer devices into the practice of most world-class companies. This fact confirms that the visualization of content is of great importance in marketing, regardless of which concept is used in the practice of the company.

Research by marketers around the world has proven that the majority of consumers prefer visuals to dry text $[11,12]$. The explosive growth of interest in Instagram and Tik-Tok clearly showed the importance of this visualization, and the use of these tools by companies has significantly increased the financial indicators of business profitability. In the presented study, it is argued that about $65 \%$ of Internet users prefer to watch training videos, and the desire to read an article increases by $80 \%$ if it contains color illustrations or a fragment of video content.

The digitalization of the world economy has led to the transfer of technologies and communications to digital, as evidenced by the fact that $93 \%$ of communications in marketing occur through visual content. Visuals are easier to remember than text, and adding data visualizations, infographics, images and videos to printed text not only makes it more interesting and engaging, but also helps to better underst cand the message being conveyed. Based on this, it is worth considering the trends in the development of content visualization, namely the influence of video and social networks and their applicability in the practice of companies around the world, which are shown in Fig. 2.

Lead generation and technological progress characterize content visualization and heavy use of social media in the context of e-marketing strategies, which have a significant impact on the level of personalization that needs to be extended to consumer interactions with brands. Therefore, traditional advertising loses its effectiveness. Personalizing your marketing messages can remedy the situation and establish a real connection between the brand and the target market. Specialized resources have learned to recognize the recipient of messages not only by name, but also to take into account his interests and the level of involvement in the transaction. The use of artificial intelligence, combined with advanced data collection and social media analytics, has made it easy to personalize everything from content to design to product recommendations. Modern trends in the development of e-marketing should be inseparably considered in conjunction with innovative technologies, gadgets and management methods.

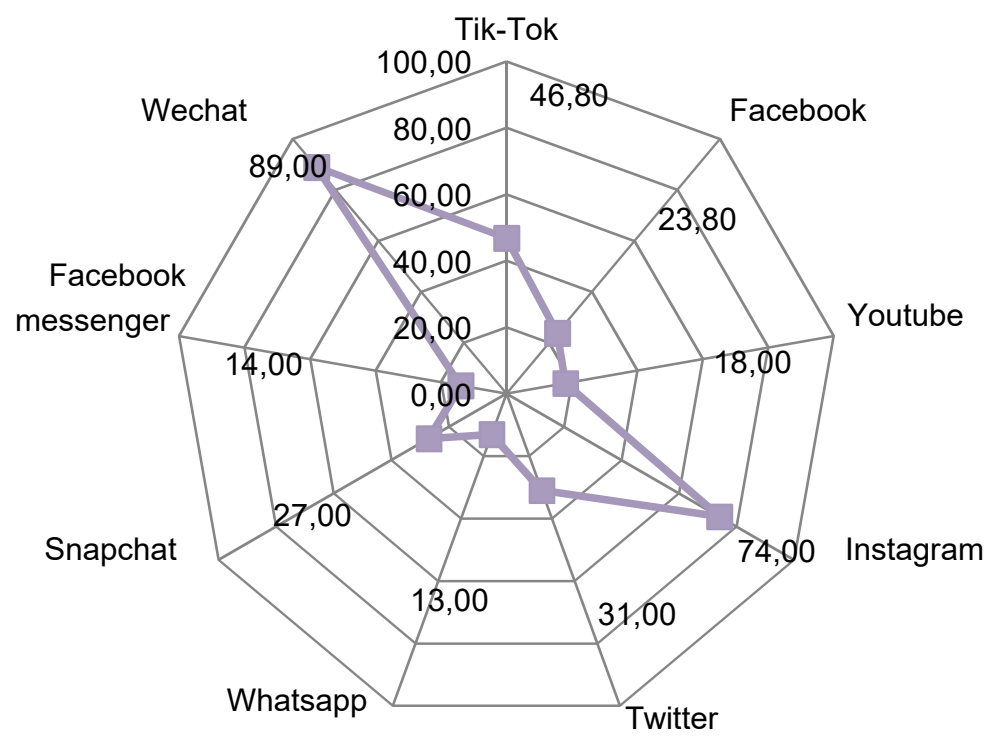

- Share of active users of social networks

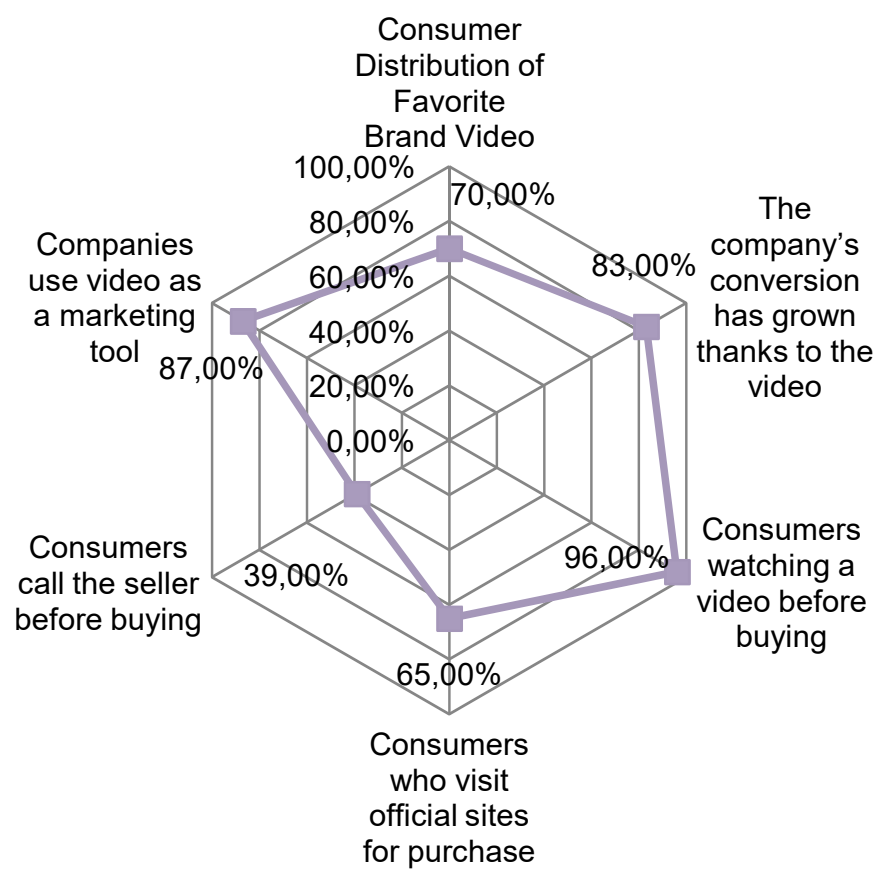

- Video as the main e-marketing tool

$b$

Fig. 2. Modern trends in content visualization in the world as of 01.01.2021, in \%: $a$-Share of active users of social networks; $b$-Video as the main e-marketing tool (developed by the author on the basis of [7]) 
Marketing and the formation of its strategy are becoming a more complex and multifaceted process on which most marketers and top managers mainly focus. Every year it becomes more difficult to develop marketing programs related to the reasons for the development of the business as a whole. Promotion goals become more complicated, marketing communications are layered, and the tasks facing marketers become more difficult and responsible. If earlier in a small business each head of the company was "his own" marketer, today more and more entrepreneurs turn to specialists for practical advice.

It is difficult to imagine modern business without specific goals and a program of clear marketing communications. Marketing planning itself has become an integral part of running a business. Strategic marketing relies on initial data about the target market, the use of digital technologies, building relationships with customers, and strengthening its presence on the Internet. This transformation is helping small businesses improve their customer experience, brand awareness and reputation. As a result, strategic marketing increases revenues and profits.

A marketing plan sets out goals and tactics for promoting a business to the market, which will rely on content marketing, SEO, email marketing, social media, contextual advertising, and offline marketing. The working paper should clearly state how each part of the marketing communications will work in the interests of the business. As a practical matter, brands are still trying to figure out how to reach rank zero, as this requires different SEO techniques than those used for regular SERP listing. If you achieve superiority in search engine optimization, then this will be a significant advantage over your competitors. The number of SEO companies offering this service over the next year is expected to grow in the near future.

One of the heavily used e-marketing tools is voice search. Voice search is showing no signs of slowing growth and will continue to have a significant impact on how leading brands create content and position themselves online. The COVID-19 pandemic and the transition to the digital segment of the global economy have had a positive impact on the development of e-marketing tools such as voice search. The dynamics of the intensity of development of innovative e-marketing tools indicates that these tools are increasingly reflected in the practical activities of world organizations, which is presented in more detail in Fig. 3.

According to global research, consumers expect increased use of voice search in the near future. Even if a company isn't ready for smart ads yet, it's important that its content is optimized for voice search. Voice search engines use search in a different way. They operate with longer queries (as in normal conversation), so optimizing content for long-tail keywords can help make it more visible for voice searches. It is important that the content contains a direct answer to the question posed.

The digitalization of the world economy and advanced industries is characterized by the fact that at this time there have been significant changes in the field of artificial intelligence. Progress in this direction was taken up by many companies, they began to use technologies based on artificial intelligence to automate and strengthen their marketing programs and business processes. Smart chatbots, contextual advertising management, voice search are examples of such implementation that we encounter more and more often in our daily life.
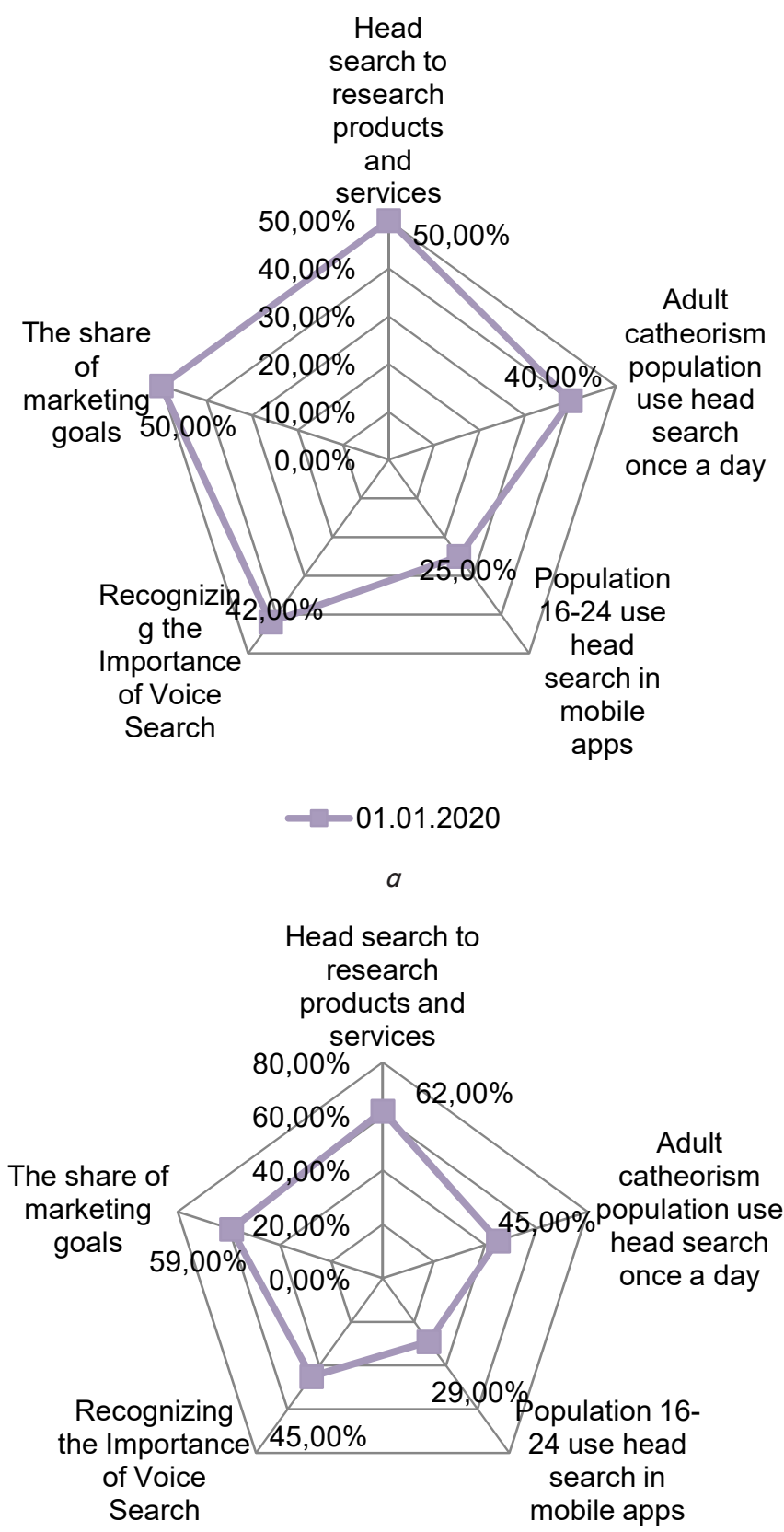

$-01.01 .2021$

$b$

Fig. 3. Global trends in the development of voice search in e-marketing in the world, in \%: $a-01.01 .2020 ; b-01.01 .2021$ (developed by the author on the basis of [7])

Big-data analytics helps companies learn more about their target audience and customers. This enables hyper-personalization of marketing messages on a large scale. Big brands are leveraging artificial intelligence technologies to strengthen their market position, freeing up resources and focusing on the customer experience, adjusting their marketing strategy to it. An important message for small businesses is an intensive transition to the automation of routine marketing processes and increases their productivity.

Regular customers are more valuable than new customers. Attracting a new customer is five times more expensive 
than retaining a loyal one. That is why it is economically justified to provide a high quality service and create an excellent customer experience. The efforts of world-class companies should be distributed in such a way as not only to constantly look for new customers, but on a regular basis to prove their necessity for regular customers. For their part, loyal customers help build reputation and brand awareness as they talk about your company to those around them.

Satisfied clients become lawyers for the company and are ready to give advice on choosing a service provider. The video, social media, live streaming, and artificial intelligence industry of streamers is incredibly popular with consumers, and people spend three times more time watching this content than pre-edited video. The effect of participation in an interesting and important event affects. This promotion technique has become the most popular way to introduce consumers to a company's product. Such content is the most attractive, since the audience is, as it were, part of the process and can partially influence it, moving from the state of passive viewing to active actions.

Live broadcasts are primarily in demand on social networks. Audiences develop the FOMO (Lost Profit Syndrome) effect if they understand that live broadcasts give them the opportunity to be the first to know the latest news, or the video contains information that they cannot get anywhere else. Based on this, it should be noted that modern trends in the development of e-marketing indicate the interactivity and diversity of innovative tools that can be used in the marketing concept. Based on the above, it is worth moving on to the methodology for determining global trends in the development of e-marketing in the world, which are presented in more detail in the next paragraph of this study.

In modern conditions, the organization of effective activities of companies is not possible without an e-marketing strategy, which includes innovative marketing tools that are based on innovations and digital technologies. The use of innovative technologies in the context of e-marketing ensures communication with customers, consumers of goods and services via the Internet, as well as the use of more communication networks, including gsm, gps, gprs, Bluetooth, Wi-Fi and the Internet.

It should be noted that digital marketing is increasingly used to refer to the targeting and interactive marketing of goods and services, which uses digital technologies to attract potential customers and retain them as consumers.

The most advanced sectors of the global economy, which intensively use digital marketing tools include the following: online stores of essential and specific goods, holdings and world-class companies in tourism and education amid the spread of the COVID-19 pandemic; financial institutions and companies; online platforms and aggregators to sell various groups of goods and services, social networks and many others. However, along with the represented sectors of the global economy, there are also sectors in which the use of digital marketing tools is minimal, for example: health and healthcare, which are already in demand; food companies; transportation companies; construction companies and others. It is worth noting that the main objectives of digital marketing are brand promotion and increasing sales through various techniques and tools. Based on this, the management of each company and organization itself determines the need to apply a particular tool or methodology of digital marketing.

Digital marketing includes a wide range of marketing tactics to promote products, services and brands. In addition to mobile technology, traditional $\mathrm{TV}$ and radio, digital marketing techniques use the Internet as the main communication intermediary. Key digital marketing activities include: search engine optimization (SEO), search engine marketing (SEM), content marketing, user-generated content (UGS), influencer marketing, content creation automation, e-commerce marketing, social media marketing (SMM), direct mail, contextual advertising, advertising in eBooks, programs, games and other forms of digital products. Channels not directly related to the Internet are also used: cell phones (SMS and MMS), callbacks, call hold tones. Arguing the above, it is worth noting that the fundamental concept of digital marketing in today's environment is a customer-centric approach.

In addition, e-marketing is beginning to penetrate into traditional types of communications, the main task of which is to capture more and more target audience for its further drag into the digital world. With a high share of competition in world markets and the need to win the loyalty of consumers, potential customers and retain existing customers, the company is increasingly trying to apply innovative marketing technologies in its activities. These technologies allow you to optimize the organizational structure of the company, reduce operating costs and increase customer loyalty using effective tools for managing consumer behavior.

However, all of the above tools are an integral part of an organization's e-marketing strategy. E-marketing in modern conditions is a key link that will ensure the effective operation of the company and its financial stability by formulating an effective marketing strategy using innovative tools. To determine modern trends in the development of e-marketing in the world, it is worth considering the dynamics of the main directions of development and use of e-marketing tools in the world, which is shown in Fig. 4.

Global trends in the digitalization of e-marketing indicate that this marketing segment in the modern world is one of the fastest-growing segments of the world market, which has the greatest consumer orientation, which contributes to intensive development trends. Based on the presented global trends in the development of digital marketing in the world, it is worth considering its distribution and use in some groups of countries, which are shown in Fig. 5.

From the presented, it is worth noting that the leader among the development of digital technologies and their application in business is China and has a significant share of sales of goods and services through digital marketing channels and is $92.8 \%$. This fact is due to the high level of digital development of the country and society, as consumers are the key objects that accept or do not accept the new product, service approach, etc. It should be noted that after China, the United States, Great Britain and Japan are the leaders in which the share of digital marketing application is slightly less, but tremendously increasing. The leaders of these countries are leaders in the world in setting new trends, technologies and tools in business.

The intensive development of e-marketing in the world is characteristic against the background of the development of digital technologies and the way people interact through the Internet. 


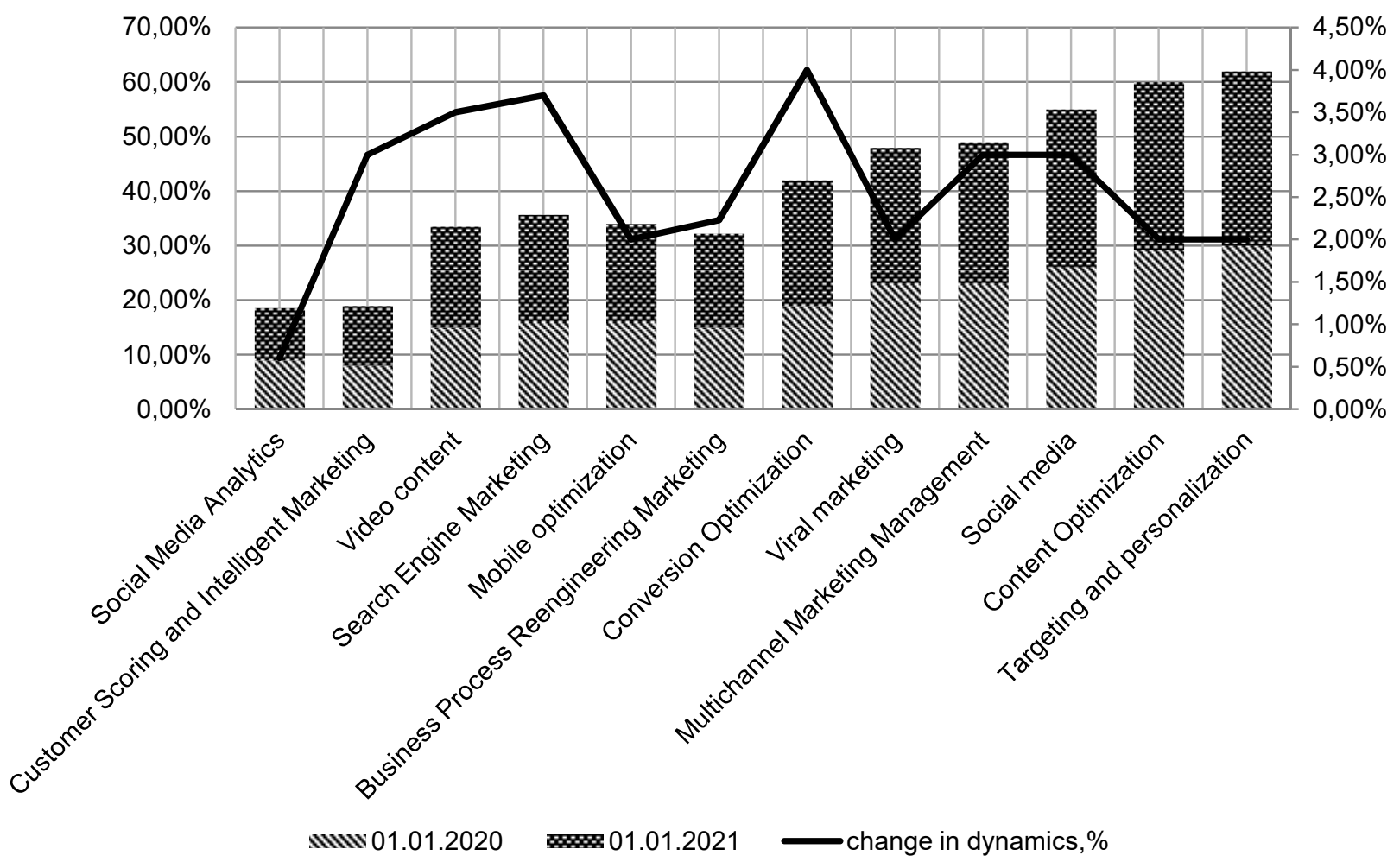

Fig. 4. Global digital trends in the development of e-marketing tools in the world, in \% (developed by the author on the basis of [7])

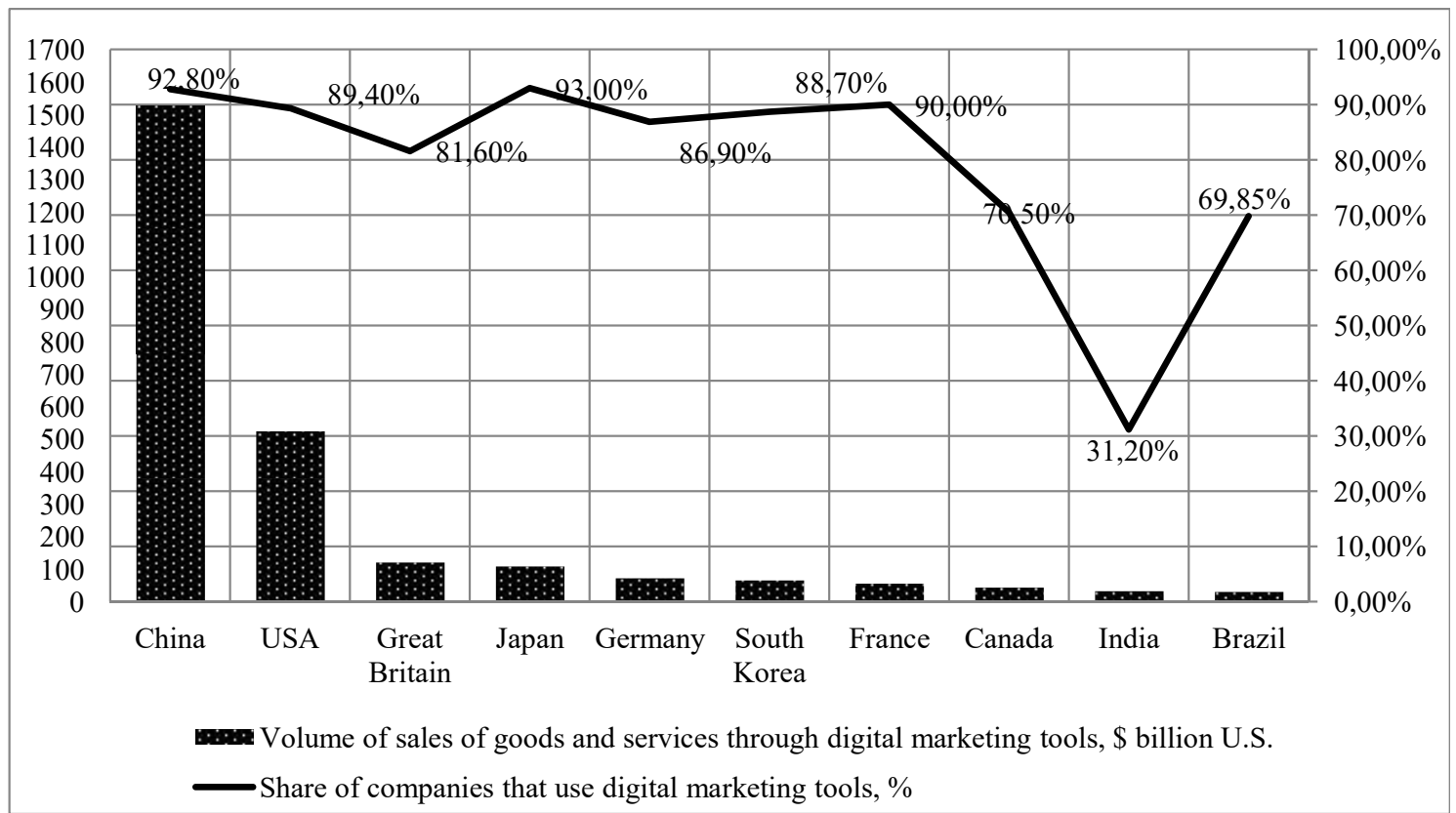

Fig. 5. Volume of sales of goods and services and share of companies in the world that use digital marketing tools

Digital tools of e-marketing in modern conditions are as follows:

1) artificial intelligence and its application in the promotion and customer service;

2) influencers and native advertising, as the main directions of promoting the goods and services of companies;

3) video marketing and streaming as a key direction of development, especially in modern conditions, when consumers buy where the product is best positioned and presented;

4) head search - an innovative tool that is characterized by the convenience and efficiency of use;
5) mobile search and micro-moments - digitalization of all spheres and branches of the world economy;

6) social networks, as the main component of promoting goods and services on the network, which is in demand;

7) protection of personal data, this tool is especially relevant due to the fact that more than $50 \%$ of services in the world are provided online and requires personalization of customers and consumers by storing data and ensuring their safety and information security $[4,5]$. 
The methodology of economic and statistical forecasting is based on previously identified trends in the development of e-marketing, which allows us to determine the cyclical nature and patterns of development processes in marketing as a whole. On the basis of the identified trends and dynamics of indicators, trends are formed, which are taken into account in the construction of the forecast and take into account the presented pattern and development trends.

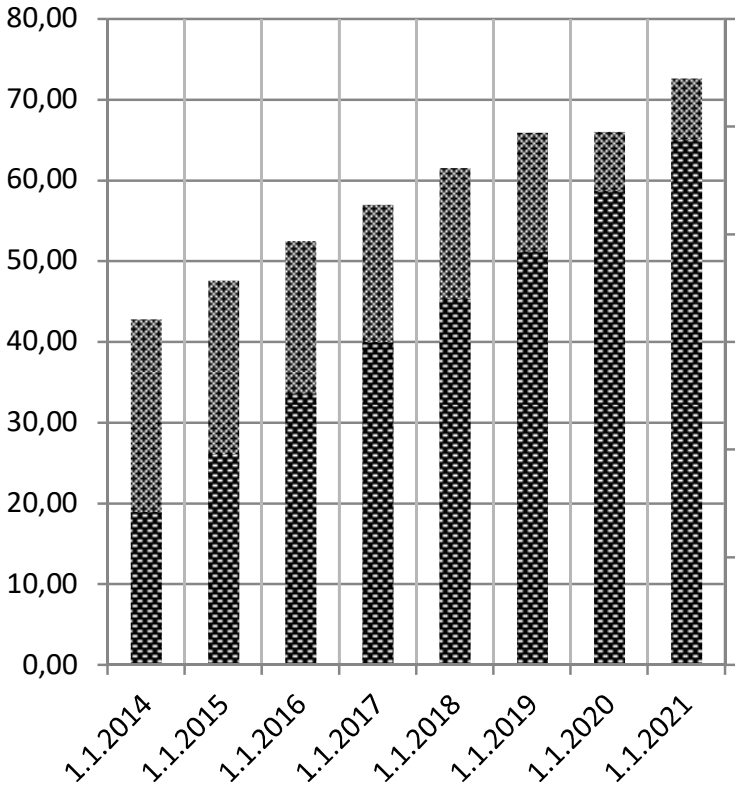

E-Marketing Revenue 쪼 E-Marketing Tool Costs $a$

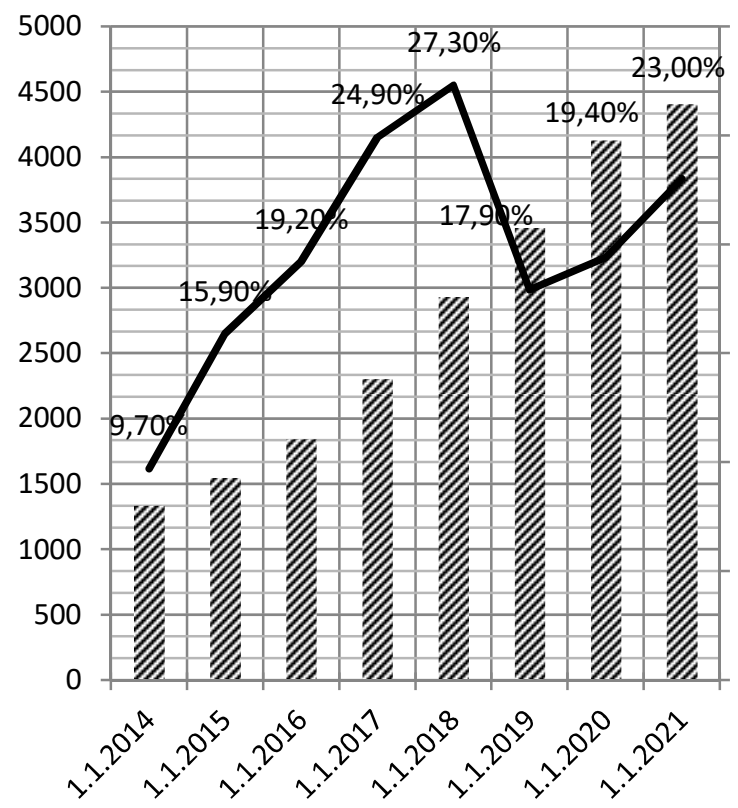

IIIIA Sales volumes using e-marketing tools, \%

$c$
6. Discussion of the results of determining global digital trends in the development of e-marketing in the world

The methodology of economic and statistical forecasting is based on previously identified trends in the development of e-marketing, which allows us to determine the cyclical nature and patterns of development processes in marketing as a whole (Fig. 6).

30,00 25,00 20,00 15,00 10,00 80,00
70,00
60,00
50,00
40,00
30,00
20,00
10,00
0,00
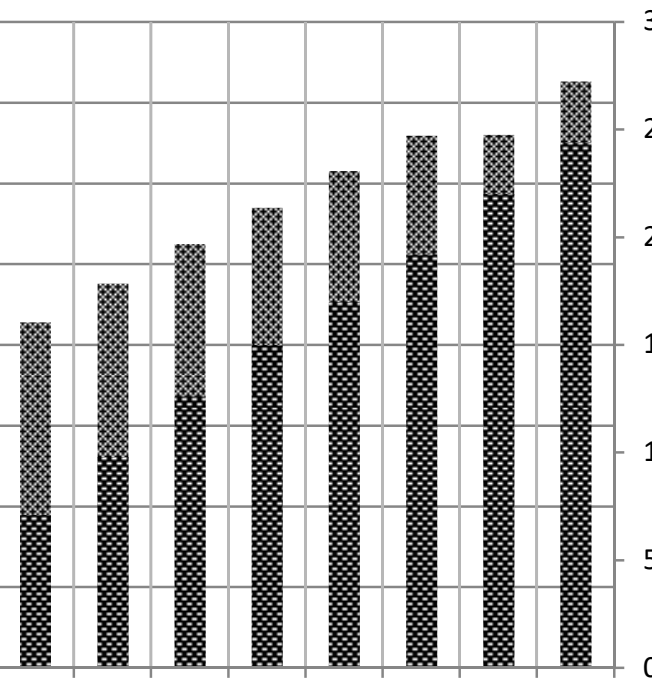
30,00 25,00 20,00

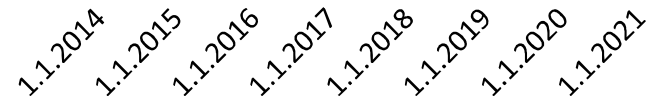

E-Marketing Revenue 효 E-Marketing Tool Costs $b$

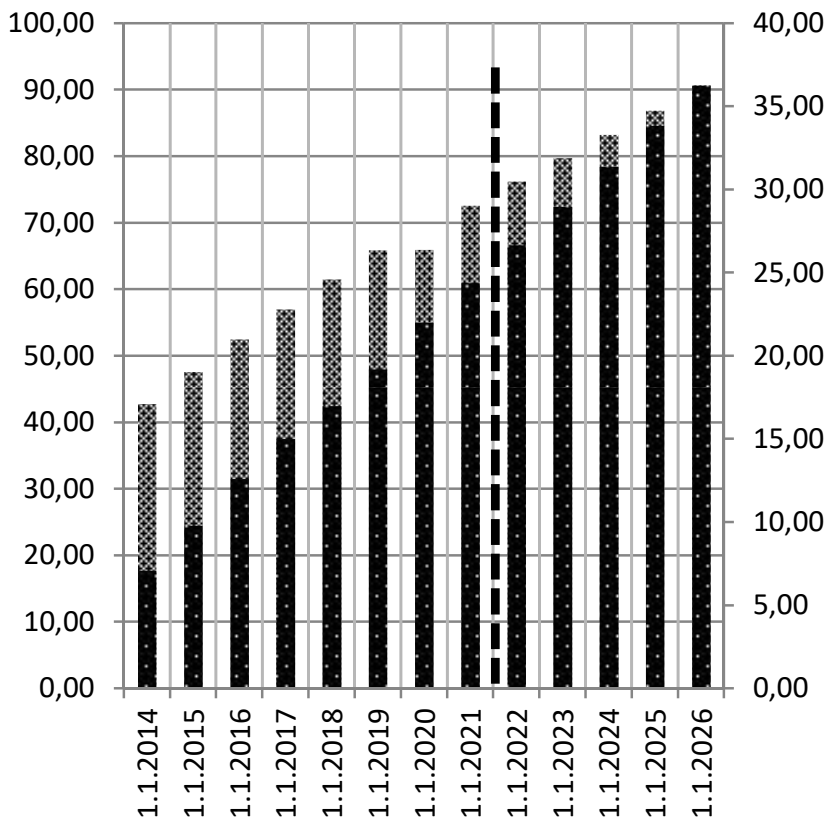

Forecast E-Marketing Revenue - Forecast E-Marketing Tool Costs

Fig. 6. Global digital trends in the development of e-marketing in the world: $a-$ E-Marketing Tool Costs, E-Marketing Revenue, \%; $b$-Sales volumes using e-marketing, $\% ; c$ - Forecast E-Marketing Tool Costs, E-Marketing Revenue, \%; $d$-Sales forecast using e-marketing tools, \% (developed by the author on the basis of [6]) 
The results of the study, namely the definition of trends, have a number of advantages and disadvantages, which should be carefully studied and taken into account when forming a marketing strategy for the future. The results of the study are accurate and reliable, which is confirmed by the adequacy of trend models and the quality of the development forecasts. Digital technology and its use in marketing have the following advantages:

1. Maximum coverage of the target audience. Some people mainly use search engines, others prefer to work with social networks, and for some, watching YouTube is their favorite pastime. If you use only one e-marketing tool, you will only be able to attract the attention of a part of your target audience. By comprehensively promoting a project, you will be able to reach all users potentially interesting to you, which platform they did not use.

2. Increased brand awareness. It is logical that contact with the audience through multiple channels at once will not allow the company to go unnoticed. Especially if display advertising and content marketing are used with publications in popular media. This effect works especially well for the service business, and in the long run.

3. Scoring the effectiveness of e-marketing channels. It is only in practice to understand which method of website promotion will be the most effective. Of course, experience allows us to make more or less accurate predictions, but reality always makes its own adjustments. By experimenting with several online advertising channels at once and comparing their effectiveness, you can gradually identify those areas that provide the greatest return on investment. Then, you can decide on the appropriate reallocation of the budget.

4. Rapid growth in traffic and sales. There are online advertising channels that provide good benefits, but require a gradual build-up, such as SEO. In contextual advertising, for example, you can start a campaign literally in a day, but the cost of a transition/lead is likely to be much higher. If you combine different directions within one complex, then the effect is balanced, and the business owner gets the opportunity to grow rapidly without losing profitability.

5. Obtaining a competitive advantage. Most players on the market, regardless of niche, rarely use more than $2-3 \mathrm{di}-$ rections of promotion on the Internet. There are also those that are limited only to SEO and contextual advertising. It is clear that when you use integrated e-marketing to promote your business, you will get a serious competitive advantage over them. Moreover, it can help to increase market share and enter the Top Players on it.

Considering the presented number of advantages of using digital technology in the framework of the formation of an organization's e-marketing strategy, it is worth highlighting the disadvantages of its use in the practice of world-class companies, namely:

1. High cost of the campaign. The more digital channels are used to build a strategy, the more budget will be required. After all, if the budget is insufficient, it will only be spraying and there will be no proper return for the business. Integrated e-marketing is rather expensive, although experienced specialists can still effectively optimize it for the capabilities of your business.

2. High requirements for the qualifications of performers. There are areas for work with which a beginner can easily cope with a year of practice. But there are also those where the main condition for effective work is extensive professional experience. If we are talking about a combination of tools and types of advertising within the complex, then the level of requirements for the professional level of performers increases significantly.

3. This option is not for everyone. This point cannot quite be characterized as a minus, but you still need to understand that integrated promotion is not suitable for everyone. If you need to cover only one city, you have a specific niche or a narrow and atypical audience, or it is concentrated within one platform, you most likely do not need complex promotion [5].

Global transformations in the global economy and its massive digitalization awaken business segments to use innovations and new e-marketing tools to promote a brand, increase conversion and improve specific positions. However, not all companies and organizations are suited to the same set of elements of the e-marketing concept to achieve the efficiency and profitability of their core business. So, for example, a combination of several channels is not suitable for everyone, but even though a higher investment is required, the potential effect is always worth the time and money spent. However, if the resources of time and money are limited in terms of the campaign budget, then it is better to gradually test each of the digital channels and its application in your e-marketing concept, comparing their effectiveness and, on the basis of this, reallocate budgets, which will allow you to rationally build a line of increasing the return on capital and increase in income.

The digitalization of the main sectors of the world economy is due to modern trends in e-marketing, which are priority for many companies. The practical use of e-marketing tools in the field of organizing marketing activities greatly simplifies the process of sales and purchases, which have become the most popular in modern business conditions. It should be noted that the use of economic and mathematical analysis and forecasting of expenses, income and sales of e-marketing is characterized by the adequacy and reliability of the received trend models, which is characterized by the significance of the criterion of the obtained models.

The obtained results of economic and mathematical analysis and long-term forecasting allow us to draw the following conclusions. Based on the above, it is worth considering the global trends in the digitalization of electronic marketing in the world. Determination of key trends in digitalization of e-marketing in the world will allow us to determine the peculiarities of the formation of trends, taking into account the intensity of the development of innovative technologies and their premium in marketing, which will serve as the basis for building a forecast based on the trends obtained. The analysis of the presented trends allows us to determine the regularity and cyclical nature of the dynamics of the main marketing processes, which ensures reliability in building a forecast based on the accumulated dynamic trends in the development of e-marketing. The dynamics of target indicators, such as the volume of sales, expenses and income directed to the use of electronic marketing tools, will become the main base of indicators for the study and application of economic and statistical analysis and forecasting for the future. The definition of global digital trends in electronic marketing on the basis of the dynamics of key indicators of expenses and income, as well as sales from electronic marketing and the future forecast of these indicators, are presented in Fig. 6.

These trends make it possible to apply a package of analysis and forecasting, taking into account the analyzed trends with further aging of the trend development models. 
The main results of the study are that the historical aspects of the formation of marketing concepts and its key elements have been considered, leading to the assertion that the developed structuring of the concept is the theoretical basis of the research. The lack of a common approach to identifying development trends and forecasting marketing developments in the world literature has been highlighted, justifying the relevance and necessity of research. The proposed approaches to economic and statistical analysis have made it possible to identify the main marketing trends and their characteristics in the world, but they do not include all the features of the world economy, so this approach may be improved.

Methodological approaches to forecasting digital marketing digitalization trends have been developed, making it possible to make an adequate forecast for the next five years. This is the main result of the research, which takes into account current trends in the transformation of the world market and elements of marketing, but is flexible enough to be supplemented by additional factors. It is important to note that the Government of the Republic of Korea has not yet done so. The theoretical aspects developed and the practical recommendations made can be applied by different companies in shaping development strategies, but may require improvement because of the specificities of the activity.

The main advantage of research is the post prognosis of the development of digital marketing for the next 5 years, taking into account the current trends of marketing development in the world. However, the uncertainty and global transformations of the world market can only be fully taken into account if development patterns are constantly modified and revised to reflect both domestic and macro-economic environments, which requires more detailed research in the future.

\section{Conclusions}

1. The main elements of the classical concept of marketing and the peculiarities of its organization in modern companies are considered. The main elements of the classical concept of marketing without which marketing is impossible are argued: product, price, advertising and place. Their specific advantages and disadvantages are determined. The results are a theory-base and a basis for planning and forming prerequisites for further development of the company taking into account classical marketing approaches.

2. Theoretical aspects and the concept of marketing are determined on the basis of the evolutionary-historical approach. This approach will make it possible to form a chronology of marketing development, its specifics and features of each element of the concept at each of the formed stages of the evolution of civilization. There are 6 key stages in the development of the concept of marketing from the end of the $19^{\text {th }}$ century to the present day. Each stage is char- acterized by the specifics of the functioning of marketing and the peculiarities of the transformation of the concept of marketing through the years. The theoretical aspects of the development of marketing are considered and determined and served as the basis for the formation of the prerequisites for the need for constant modification of approaches to the organization of marketing activities.

3. Historical and evolutionary approaches to the analysis of marketing concepts and features of its development made it possible to substantiate the need to revise the management strategies of companies, taking into account current trends. These assumptions are based on the conceptual need to use the basic tools and elements of the electronic marketing concept, taking into account modern development trends. The revision of management strategies is argued and due to the fact that in the context of a pandemic and exacerbation of uncertainty processes, there is an urgent need to quickly change marketing activities, as well as optimize existing business processes of companies in order to minimize financial losses and increase efficiency. The transformation of the world economy is characterized by abrupt changes and reformatting of long-known management formats, which is confirmed by the expansion of marketing elements and the emergence of new $6 \mathrm{P}-12 \mathrm{P}$ concepts, where marketing elements depend on the specifics of the company and the ability to intensively adapt.

4. The specificity of marketing transformation in modern conditions is argued. A close relationship between marketing and consumers was revealed (in which marketing significantly depends on the mood and behavior of consumers, which change rapidly). This fact is confirmed by the fact that the more users use Internet technologies, the more they need remote services, purchases and consultations. This fact is confirmed by research on the number of active users of social networks, users who use voice search and video content to purchase goods and services. All the studied features made it possible to determine the main features of the transformation of marketing and its optimization through the digitalization of its main elements.

5. The obtained trend models, based on the use of economic and statistical forecasting, confirm the main results of the study conducted as part of determining global trends in the development of digital marketing in the world. The adequacy and reliability of the obtained trend models based on the R2 criterion, which is more than 0.89 , allows us to confirm the correctness of the forecast and the possibility of its application in the practical activities of companies. And the predicted sales volumes using e-marketing and their variation in percentage points are on average in the range of $23 \%$, which corresponds to the indicators for the analysis of trends of indicators, which acted as an information base and are the basis for building a forecast. All analyzed indicators related to the use of tools and e-marketing technologies, as well as the developed assessment and forecasting methodology, made it possible to determine the trend for the next 5 years in the future.

\section{References}

1. Saura, J. R. (2021). Using Data Sciences in Digital Marketing: Framework, methods, and performance metrics. Journal of Innovation \& Knowledge, 6 (2), 92-102. doi: https://doi.org/10.1016/j.jik.2020.08.001

2. Coyne, M. (2020). Three Sticks Wines: Digital Marketing, Branding, and Hospitality During a Crisis. Wine Business Journal, 4 (2). doi: https://doi.org/10.26813/001c.22071 
3. Tikhonov, G. V., Lavrova, L. A., Kolosova, V. V., Zemlyanskaya, N. B., Kazakova, N. V. (2020). Marketing as an Effective Control of Progressive Innovations. TEM Journal, 9 (3), 1094-1099. doi: https://doi.org/10.18421/tem93-34

4. Sadchenko, O. V. (2020). Basic directions of experience economy marketing development in conditions of sustainable development. Economic Innovations, 22 (2 (75)), 101-111. doi: https://doi.org/10.31520/ei.2020.22.2(75).101-111

5. Al-Ababneh, H. 2021. Marketing and logistics: features of functioning during the pandemic. Acta logistica, 8(2), 175-187. https:// doi.org/10.22306/al.v8i2.221

6. Rabby, F., Chimhundu, R., Hassan, R. (2021). The elucidation of marketing trends and a post-positivist approach to understand consumer behaviour - a review. Journal of Tianjin University Science and Technology, 54 (8), 13-32. doi: https://doi.org/10.17605/ OSF.IO/4C8YH

7. Herhausen, D., Miočević, D., Morgan, R. E., Kleijnen, M. H. P. (2020). The digital marketing capabilities gap. Industrial Marketing Management, 90, 276-290. doi: https://doi.org/10.1016/j.indmarman.2020.07.022

8. Abdul Lasi, M. bin, Mohamed Salim, S. (2020). The relationship between e- marketing mix strategy and integrated marketing communication: a conceptual framework. International Journal of Engineering Applied Sciences and Technology, 5 (6), 40-48. doi: https://doi.org/10.33564/ijeast.2020.v05i06.007

9. McDermott, M., Gullekson, N., Kiersch, C., Tempski, D. (2021). Improving mastery of principles of marketing concepts through interdisciplinary learning and integrated business projects. Marketing Education Review, 31 (2), 183-189. doi: https://doi.org/10.1080/ 10528008.2021.1908834

10. Reavey, B. (2020). Using scholarship applications to aid knowledge transfer of key marketing concepts. Marketing Education Review, 30 (2), 98-104. doi: https://doi.org/10.1080/10528008.2020.1756340

11. Al-Ababneh, H. (2019). Concept of Internet Marketing as a Modern Organization Development Paradigm. International Journal of Innovative Technology and Exploring Engineering (IJITEE), 9 (1), 2654-2661. doi: https://doi.org/10.35940/ijitee.13394.119119

12. Li, L., Shen, Y. (2021). Research Trend of Green Finance in China Based on Co-word cluster Analysis. The Sixth International Conference on Information Management and Technology. doi: https://doi.org/10.1145/3465631.3465719 